\title{
Entre dos mundos: Generaciones, identidades y disputas culturales de la comunidad boliviana de Quilmes (1980-2016)
}

\author{
Between two worlds: generations, identities and cultural disputes of the Bolivian \\ community of Quilmes (1980-2016)
}

\author{
Stefania Cardonetti \\ stefaniacardonetti91@gmail.com \\ Universidad Nacional de Quilmes - CONICET, \\ Argentina
}

Recepción: 06 Enero 2020

Aprobación: 22 Junio 2020

Publicación: 01 Septiembre 2021

Cita sugerida: Cardonetti, S. (2021). Entre dos mundos: Generaciones, identidades y disputas culturales de la comunidad boliviana de Quilmes (1980-2016). Sociohistórica, 48, e141. https://doi.org/10.24215/18521606e141

\begin{abstract}
Resumen: El presente artículo se propone indagar, mediante el ritual conocido como "Danza de los Caporales", en un conjunto de procesos de significación y resignificación de la identidad cultural boliviana en la Argentina y específicamente en la ciudad de Quilmes, con el fin de aprehender y comprender las complejidades de la interacción entre culturas vernáculas e identidad nacional que se disputan en el escenario público de una sociedad impactada por procesos migratorios de diferente origen. Proponemos explorar las relaciones entre procesos de movilidad social y económica de la comunidad migrante y ocupación de espacios simbólicos de poder cultural, y analizar el uso, significación y resignificación de prácticas culturales en distintas generaciones de un grupo inmigrante.
\end{abstract}

Palabras clave: Inmigración, Identidad, Generaciones, Cultura.

Abstract: The present article has the purpose to research through the ritual known as Danza de los Caporales a set of processes of signification and resignification of the Bolivian cultural identity in Argentina and specifically in the city of Quilmes, to apprehend and understand the complexities of the interaction between vernacular cultures and national identity that are disputed in the public scenario of a society impacted by migratory processes of different origins. We propose to explore the relation between processes of social and economic mobility of the migrant community and occupation of symbolic spaces of cultural power and analyze the use, signification and resignification of cultural practices in different generations of an immigrant group.

Keywords: Immigration, Identity, Generations, Culture.

\section{INTRODUCCIÓN}

Desde la década de 1980, en la Argentina el fenómeno de las migraciones internacionales ha constituido un campo de interés para la historiografía, sobre todo debido a que es considerado uno de los factores constitutivos de la identidad nacional. Sin embargo, en esa imagen que vincula la inmigración con el relato fundacional quedaron largamente al margen los movimientos de población de los países limítrofes, un flujo cada vez más creciente y visible durante la segunda mitad del siglo XX, del que se ocuparon las ciencias sociales, en particular la sociología y la antropología, poniendo el foco, en particular, en los inmigrantes bolivianos. No 
fue sino hasta hace menos de un lustro que la historia comenzó a mostrar interés por este fenómeno, quizá porque, como lo señala la historiadora Carina Cassanello (2016), el flujo viró desde movimientos estacionales y temporarios a una migración de asentamiento.

Entre las dimensiones que privilegiaron esas disciplinas se cuenta el estudio de las redes sociales, las dinámicas de inserción en el mercado laboral y los patrones de asentamiento. Asimismo, y especialmente desde la antropología, se han estudiado las formas que adoptan la exclusión y la discriminación de las que este colectivo es objeto en la sociedad local. Estos enfoques configuraron una visión canónica dentro de los estudios sobre los inmigrantes bolivianos: se trata de una mirada recurrente según la cual los inmigrantes son ubicados en la condición de sujetos subalternos y abordados a partir de su situación de vulnerabilidad (Grimson 1999; Benencia 2004; Pizarro 2007).

En un abordaje que intenta superar la perspectiva de los bolivianos como sujetos subalternos, en este artículo nos proponemos analizar el complejo proceso de construcción de identidad étnica asociado a la dinámica de inserción del grupo en la sociedad receptora y a la puesta en valor de sus tramas vernáculas como forma de disputar un espacio de poder cultural. Para ello, enfocaremos nuestro análisis en la Danza de los Caporales practicada por los hijos de una pequeña comunidad de inmigrantes bolivianos de la localidad de Quilmes, un diacrítico que, como veremos, nos permite comprender el desarrollo de la etnicidad a la luz de los cambios generacionales.

Desde el punto de vista del abordaje de nuestro objeto, es necesario señalar que nos basamos fundamentalmente en el uso de fuentes orales. Estas narrativas personales constituyeron nuestro principal insumo pero fueron completadas y cruzadas con otras fuentes que permitieron corroborar el crecimiento de las fraternidades de Caporales; especialmente, nos referimos a los registros difundidos por una de las asociaciones que nuclea a estos conjuntos folklóricos. Asimismo, acudimos a la prensa local para relevar noticias y crónicas sobre la participación de los Caporales de Quilmes en diferentes actividades en el espacio público.

La mayoría de los estudios sobre las estrategias de integración de comunidades de inmigrantes puso el foco tanto en las respuestas que los grupos étnicos daban a iniciativas que provenían del Estado como en el rol crucial que jugaron los liderazgos políticos, económicos e intelectuales (Conzen, Morawska \& Vecoli, 1991; Bertoni, 2001; Devoto, 2003; Bjerg, 2009). Esta tradición epistemológica prestó escasa atención a las dinámicas internas y a las intenciones y apuestas que los inmigrantes desplegaban para recrearse a sí mismos en busca de un lugar en la sociedad de destino. Desde nuestra perspectiva, reflexionar sobre la disputa de poder cultural que llevan a cabo los bolivianos de primera y segunda generación requiere centrar la atención en los espacios culturales y económicos más significativos del grupo.

A diferencia de aquellos trabajos, en nuestro caso no encontraremos líderes políticos, intelectuales o económicos en el sentido clásico; sin embargo, los espacios -laborales, de sociabilidad y privadossignificativos en las trayectorias de este grupo nos orientaron en la búsqueda. Las prácticas inherentes a esos sitios, la simbología y los valores que allí se despliegan hicieron posible la constitución de múltiples identidades relacionadas en distintos niveles, aquello que Gjerde (1999) denominó "identidades complementarias".

Proponemos comprender la configuración de identidades complementarias en el marco de la disputa por el poder cultural, un fenómeno que implica reconocer las estrategias que dichas comunidades desarrollan para delinear espacios de diferenciación con la sociedad local pero también para entretejer sentidos dominantes y definiciones en el interior de la comunidad. Son procesos complejos que configurarán una identidad étnica en permanente movimiento, mediante la cual se integrarán al tejido social. En la Argentina, y como analizaremos con mayor profundidad más adelante, la autoafirmación identitaria de las comunidades migrantes implica pensar en clave institucional (como las prácticas asociacionistas de los inmigrantes de la etapa aluvial, largamente estudiadas por la historiografía argentina) en liderazgos étnicos, celebraciones 
ritualizadas expresadas en el espacio público y la creación de relatos y referencias para visibilizar tanto las diferencias como los deseos de integración a la sociedad local.

Esta idea nos permite entender la etnicidad en sus múltiples niveles y en su dinámica. Las identidades a las que nos referimos son aquellas que se han constituido no sólo en el tiempo, sino fundamentalmente en los espacios y a través de las generaciones que interesan a este artículo. Creemos que los inmigrantes bolivianos y sus hijos pudieron desplegar múltiples lealtades a lo largo de sus trayectorias, y configuraron etapas de despertar y de letargo de las identidades.

Es cierto que la generación puede ser empleada en un sentido "biológico", en referencia a las generaciones de una familia (abuelos, padres, hijos, etc.). En muchos sentidos, nuestra concepción es biológica, en tanto que consideramos primera generación a la de los padres-inmigrantes y segunda a la de los hijos independientemente del lugar de nacimiento, porque lo que nos interesa es que hayan sido socializados en la Argentina.

En este artículo, el sentido social del concepto de generación es relevante porque aunque lo biológico pueda superponerse, la experiencia de migrar establece un punto de posibles conflictos entre padres e hijos en relación con la valoración diferencial que ambas generaciones tienen de la cultura boliviana en el escenario de la sociedad argentina. En este sentido, el marcador generacional esencial es la migración. Los padres, además de haber nacido antes (generación biológica), emigraron de su lugar de origen, mientras que los hijos no lo hicieron, y si ese fue el caso, ocurrió en una edad tan temprana como para realizar el grueso de la socialización en la Argentina. ${ }^{1}$

Dado que este trabajo parte de un enfoque generacional, resulta adecuado utilizar la categoría generaciones como un recurso para abordar el problema de la disputa por el poder cultural, que se materializa en la segunda generación de bolivianos y tiene su manifestación más elocuente en la participación de Los Caporales en la fiesta y peregrinación en honor a la virgen de Copacabana que se realiza todos los meses de agosto en la Basílica de Luján, un sitio emblemático del catolicismo y de la identidad nacional argentina.

\section{Caporales y peregrinos. La fiesta de la Virgen de Copacabana en la ciudad de LuJÁN}

La larga historia de peregrinaciones hacia la ciudad de Luján comienza a finales del siglo XIX cuando parroquias, congregaciones y comunidades de inmigrantes se organizaban para caminar hacia el santuario. En los estudios que se han ocupado de analizar el peso y el significado que en la historia argentina tienen las peregrinaciones a Luján, sólo algunos grupos tienen un lugar de privilegio. Entre ellos podemos mencionar a la comunidad italiana, que ocupa un lugar distinguido por la capacidad de movilización que demostró desde la primera década del siglo XX, cuando en vísperas del Centenario peregrinó por primera vez; o la francesa, que tempranamente proclamaba: "Todas las naciones representadas en la Argentina tienen colocada su bandera respectiva en el santuario nacional (...) tan sólo faltan allí los colores franceses” (Lida, 2010, p. 815). Evidentemente, en la primera década del siglo XX formar parte del colectivo de comunidades que se hacían de un lugar en ese espacio público se había vuelto de importancia.

Podríamos ubicar estas primeras expresiones como el inicio de lo que sería una extensa historia de peregrinaciones a la ciudad de Luján. Pero, así como dentro de la disciplina histórica la inmigración boliviana a la Argentina ha suscitado menos interés que la inmigración transatlántica, debemos destacar que algo similar sucede con la peregrinación boliviana a Luján. Sin embargo, argüimos que en los intersticios de la historia nacional de la Argentina, impactada fuertemente por el fenómeno de la inmigración, la colectividad boliviana, al igual que otras comunidades emigradas, ha tejido su participación dentro del concierto de personas que desfilan por la ciudad bonaerense.

Actualmente, la cripta emplazada en la Basílica contiene más de cincuenta imágenes de la Virgen María, en sus distintas advocaciones; la mayoría de ellas, representantes de países americanos. Entre ellas, se encuentra 
Nuestra Señora de Copacabana, patrona de Bolivia. Como muestra de devoción, desde el año 1956, en el último tramo del invierno, parte de la comunidad boliviana se moviliza hacia Lujan para dar lugar a una de las peregrinaciones más coloridas del año.

Durante esta festividad desfilan decenas de grupos que ofrecen al público una variedad de danzas de origen andino, entre ellas la Morenada y los Tinkus. Sin embargo, en el año 2010, cuando se celebraba la $54^{\circ}$ edición de la festividad, de los cincuenta grupos que desfilaron, treinta y seis representaron la Danza de los Caporales. Asimismo, en el año 2016, de los noventa y ocho conjuntos participantes, sesenta bailaron Caporales. Así lo indican los registros de la Asociación de Conjuntos Folklóricos de Residentes Bolivianos en Argentina. Estos datos nos advierten sobre el crecimiento general de la participación de grupos de bailarines en términos cuantitativos y en particular de la danza de la que nos ocupamos en este trabajo. ${ }^{2}$

Practicar la danza de Los Caporales implica formar parte de agrupaciones denominadas "fraternidades" y todas ellas comparten, generalmente, una misma estructura de organización interna. La fraternidad se encuentra jerárquicamente constituida, los guías cumplen el papel de ordenar las festividades más importantes y además se abocan a la tarea de dirigir a la "tropa" de fraternos (el conjunto de bailarines). Dentro de ésta, por un lado, las "cholitas" son lideradas por una guía que les enseña los sutiles movimientos que deben realizar, el cuidado de la vestimenta y cuestiones relacionadas con el comportamiento de las mujeres en el grupo. Por otro lado, la tropa de "machos" es acompañada por un guía masculino que muestra cómo debe expresarse un verdadero caporal, con movimientos fuertes y ágiles.

Además, el funcionamiento y la reproducción de la fraternidad requiere de la conformación de una comisión directiva, en la cual la tesorería es la pieza más importante, ya que la recaudación representa una condición central para formar parte del concierto de fraternidades dispuestas a ganar un lugar de privilegio en el espacio público. Por la experiencia de Los Caporales de Quilmes corroboramos que las cuotas mensuales que se abonan son utilizadas para costear bandas musicales que acompañan las peregrinaciones y que son el insumo esencial para posicionarse en un lugar destacado, pero el dinero también se utiliza para afrontar el alquiler de la sociedad de fomento en la que se llevan a cabo los ensayos y permite costear el transporte, entre otros insumos.

Esta danza es dirigida y representada por jóvenes bolivianos de segunda generación. Este fenómeno no pasa inadvertido para el conductor de la festividad en Luján quien, cuando las fraternidades desfilan frente al altar de la virgen, proclama desde el escenario: "Ésta es nuestra siembra, son jóvenes que ya forman parte de nuestra comunidad". ${ }^{3}$ Alude así a la forma en que sujetos nacidos en la Argentina llevan adelante la puesta en valor de lo que para ellos representa la identidad boliviana. A continuación, proponemos comprender las condiciones de posibilidad de esta reconfiguración identitaria en los espacios de significación de la comunidad.

\section{Entre El mercado y la comunidad étnica. Disputa Cultural y Recreación IDENTITARIA}

En el caso que estudiamos, y como adelantamos en las primeras páginas de este artículo, comprender la disputa por el poder cultural de los migrantes bolivianos supone poner el foco en la cuestión espacial y en las prácticas culturales que ellos desarrollan en los lugares en los que se desempeñan como trabajadores y donde transcurre gran parte de su vida social, ya que allí pueden desplegar símbolos y valores para recrear su identidad y afianzar el sentido de comunidad étnica. Por ello, en las siguientes líneas nos ocuparemos de esa cuestión de vital importancia para nuestra interpretación.

Los primeros registros de la inmigración boliviana en la Argentina datan de 1869, cuando se realizó el censo nacional de población. En ese entonces su presencia no era significativa, sobre todo si la comparamos con otras comunidades. Sin embargo, en las últimas tres décadas del siglo este flujo creció considerablemente y también se incrementó el nivel de concentración en espacios en donde los bolivianos se volvieron más visibles, especialmente en el Gran Buenos Aires y la Ciudad Autónoma de Buenos Aires (Cassanello, 2016). 
Luego de cruzar la frontera, la vida laboral de los bolivianos incluyó derroteros por distintas ramas hasta encontrar una actividad estable. Tomemos por caso a Nélida, ${ }^{4}$ quien llegó a Buenos Aires en 1973, trabajó como empleada doméstica, posteriormente como vendedora ambulante en las calles y luego en el Mercado Frutihortícola de Berazategui. Junto con su esposo pudo alquilar un puesto en ese sitio, dominado por ese entonces por inmigrantes italianos y portugueses a los que estos recién llegados desplazarían gradualmente mediante un proceso que a partir de 1970 ubicó a los bolivianos como protagonistas y los posicionó en distintos eslabones de la cadena de producción y comercialización hortícola, que hasta entonces remitía a tradiciones y prácticas traídas por los inmigrantes europeos.

Los investigadores señalan que, a partir de los años 1990 (Benencia, 1997; Pizarro, 2007), los bolivianos ya contaban con el predominio en la actividad frutihortícola de abastecimiento al mercado interno. En el caso que estudiamos, podemos afirmar que desde la década de 1980 hasta la actualidad, tanto el Mercado de Berazategui, uno de los núcleos de la bolivianidad del conurbano sur, como las ferias itinerantes y algunos barrios de la localidad de Ezpeleta (en los cuales surgieron las primeras fraternidades de Caporales), se tiñeron de una cultura boliviana recreada por los distintos actores de la comunidad de inmigrantes a través de las generaciones.

En estas etapas de configuración y reconfiguración, el grupo desplegó prácticas colectivas mediante las cuales se diferenciaron de la sociedad local y afianzaron un sentido de comunidad étnica. Entre esas prácticas podemos destacar criterios particulares sobre la maternidad, el cuidado de la infancia y la familia, una interpretación y ostentación de la movilidad social y económica que se expresa en luchas simbólicas por obtener prestigio y status, y formas de organizar el espacio desplegando símbolos que aluden a un pasado compartido y delimitan las fronteras del grupo.

Como acabamos de mencionar, el Mercado Frutihortícola de Berazategui es uno de los espacios cruciales para comprender la dinámica de la reconfiguración étnica de nuestro grupo de estudio. Está situado sobre la calle Dardo Rocha en intersección con la Avenida Varela. En la fachada se lee, del lado derecho: "Mercado Mayorista Frutihortícola" y, del izquierdo: "Productores del Sud S.A", en referencia a la sociedad (de la que no participan los puesteros bolivianos) que administra el predio y que mantiene las relaciones institucionales con organismos gubernamentales. Por medio de las fotografías y los relatos de nuestros entrevistados, pudimos observar que desde la década de 1990 hasta la actualidad el mercado duplicó sus dimensiones.

El sociólogo visual Jeromé Krase (2009) afirma que, cuando los inmigrantes crean nuevos hogares transnacionales, cambian la apariencia y el significado de los espacios urbanos y, al mismo tiempo, sus prácticas espaciales desafían a la cultura dominante en cuanto a la definición de estos terrenos disputados. Consideramos, como Krase, que cuando alguien cambia visualmente un espacio, cambia su significado. En este punto, es pertinente preguntarnos en qué consistió la apropiación espacial del Mercado por parte de los bolivianos. El despliegue visual se hizo por medio de estrategias que incluyen, por ejemplo, la colocación de banderas en cada uno de los puestos que ocupaban o la ornamentación del lugar de trabajo con objetos traídos de Bolivia.

Es de destacar que dentro de este enclave abundan las banderas bolivianas; no obstante, en la mayoría de los casos, al lado de éstas (a las que el tiempo ha desgastado) encontramos la insignia argentina. Esta conjunción, a nuestro juicio, evidencia un sentido de doble lealtad: a la comunidad étnica que se congrega en el Mercado y al país de adopción. No consideramos que los inmigrantes ostenten la bandera boliviana como una forma de evocar y rememorar una identidad esencial apegada al lugar de origen. Por el contrario: como señaló Stuart Hall (2010), la identidad cultural "no es algo que ya exista, trascendiendo el lugar, el tiempo, la historia y la cultura”. A nuestro juicio, todo proceso identitario requiere marcar límites simbólicos en un juego de diferencias que, en este caso, involucra lo boliviano y lo argentino.

En ese sentido, la exposición de esas insignias permite distinguir a la comunidad étnica de la sociedad local y, al mismo tiempo, muestra que hay múltiples maneras de configurar y expresar identidades culturales. Por ejemplo, exhibiendo los símbolos patrios argentinos en una demostración de reconocimiento y respeto y, al 
mismo tiempo, sosteniendo selectivamente patrones culturales del país de origen y regulando las costumbres y las formas de sociabilidad tradicionales.

Hasta aquí, estamos comprendiendo cómo los inmigrantes se congregaron en un espacio reducido donde era más factible reconocerse como comunidad, en la medida que los paisanos se encontraban en un mismo sitio, trabajando en una actividad comercial que conocían bien. Por estos motivos, proponemos recuperar la mirada de los protagonistas.

Nélida Hinojosa tiene 62 años y Miguel Ferrufino, 65; son inmigrantes bolivianos y desde hace treinta años trabajan en el puesto 31 . Actualmente tienen cuatro empleados y cuentan con la ayuda de sus dos hijas, que, aunque tienen sus propios puestos, colaboran con ellos. El derrotero de Nélida y Miguel incluye el tránsito por otros espacios laborales. Nélida trabajó como empleada doméstica y textil, y posteriormente como vendedora ambulante de productos frescos junto a su hermana, mientras que su esposo fue obrero metalúrgico hasta que encontraron la estabilidad dentro del Mercado mediante una actividad que ella ya realizaba de forma ambulante y a la que su marido se incorporó. Nélida relata que comenzó a trabajar con Miguel en un pequeño puesto en el que vendían especias, mientras que los italianos todavía se ocupaban de comercializar frutas y verduras de forma mayorista.

La trayectoria de Nélida no constituye un caso excepcional. Las formas de inserción de las bolivianas en el mercado laboral han sido abordadas desde las ciencias sociales, por ejemplo en los trabajos de la socióloga Gloria Ardaya (1986), que estudió tempranamente la venta ambulante. Según la autora, las mujeres suelen transitar por distintos empleos dentro del sector informal. Uno de los más comunes es el pasaje del servicio doméstico a la venta ambulante, porque esta última tiene la particularidad de permitirles, cuando se convierten en madres, concurrir con sus hijos. Para las madres de los jóvenes entrevistados, la venta ambulante apareció como una opción cuando se instalaron en el conurbano bonaerense. Asimismo, contamos con el relato de Nélida, quien narró en primera persona la experiencia de la venta ambulante. Estas fuentes orales nos permitieron dilucidar cómo se comenzaba a articular una subjetividad migrante y cómo se fue construyendo un marco de significación compartido dentro de las primeras actividades laborales.

Para Nélida, la venta ambulante apareció como una posibilidad cuando tuvo su primer hijo. En ese momento acordó con su hermana trabajar en puestos itinerantes. De esa manera podían compartir la crianza de sus hijos durante la jornada porque, a veces, salían ambas a vender y otras veces los niños se quedaban con alguna de ellas en el hogar, mientras que la otra vendía en la vía pública. Aunque la venta ambulante supone dispersiones espaciales, en ella podemos vislumbrar los primeros lazos de identificación de la comunidad boliviana en el conurbano sur. Además, no se trata solamente de un medio de subsistencia, sino que también forma parte de una trama cultural que encuentra sus orígenes en Bolivia y que supone formas de reciprocidad y de articulación de relaciones familiares y, al mismo tiempo, es un lugar donde las paisanas comparten prácticas, valores, costumbres y un mismo idioma, por ejemplo Nélida cuando llegó a la Argentina solo hablaba en quechua. De este modo, ella y sus compatriotas desplegaron dentro del Mercado una forma particular de ejercer la maternidad: ellas consideraban como la mejor opción llevar los hijos consigo, cargándolos en los aguayos a sus espaldas. Con el paso del tiempo, esos niños comenzarían a colaborar con sus progenitores en los puestos. Por ello, concebimos el Mercado como un espacio económico pero también como un espacio de socialización, cultural y emocional donde, como veremos, se originaron las primeras tensiones entre la generación de los inmigrantes y la de sus hijos. 


\section{ENTRE DOS MUNDOS}

La primera generación se apropiaba de los espacios que mencionamos en las páginas anteriores y, al mismo tiempo, moldeaba un pequeño mundo donde las siguientes generaciones se socializaron. Yésica nació en 1990 en la ciudad de Quilmes y es la hija menor de un matrimonio boliviano que emigró en la década de 1970. Sus padres forman parte de las personas que fueron expulsadas de la Villa 31, en el barrio de Retiro, a finales de la década de 1970 por las políticas de urbanización de la Ciudad de Buenos Aires implementadas por la última dictadura militar, políticas que incluyeron un plan de erradicación de las villas de emergencia para la creación de autopistas. Esta historia le fue transmitida por sus padres y, de algún modo, se proyecta en el presente de nuestra entrevistada. Por eso, Yésica puede evocarla con la nitidez de una experiencia propia:

Mis papás se conocieron en la Villa 31. Siendo de Bolivia, ellos vinieron acá cada uno por su camino, cada uno de diferente manera y se conocieron acá. Después se juntaron, formaron familia y fue ahí donde compraron el terreno donde yo me crie, donde yo nací. 5

Este matrimonio se insertó a finales de la década de 1980 como puesteros en el Mercado Frutihortícola de Berazategui, luego de un derrotero clásico por otros rubros: el metalúrgico en el caso del padre, el empleo doméstico y la venta ambulante en el de su madre. La configuración de la subjetividad de Yésica durante la niñez, como la de otros niños de la comunidad boliviana, transcurrió en espacios de socialización disímiles. Por un lado, la escuela pública argentina, en la que manifiesta haberse sentido cómoda y donde entabló sus primeras amistades. Ella logró conformar un grupo de amigas con las que compartía tanto las actividades escolares, como recreativas, cumpleaños u otros encuentros sociales. En ese momento, manifiesta que "no se veían las diferencias". Sin embargo, cuando Yésica evoca su experiencia escolar, lo "no dicho" se nos aparece como parte sustantiva de su tránsito por la escuela.

Ante sus compañeros y docentes, durante el proceso de escolarización, un fragmento de su experiencia podría conceptualizarse, siguiendo al especialista en memoria Michael Pollak, como "lo inconfesable" (Pollak, 1989). Es decir, aquellos silencios que se enmarcan en un temor a exponerse a malentendidos o a experimentar un castigo (material o simbólico). Esas memorias, según el autor, esperan la ocasión para invadir el espacio público y pasar de lo "no-dicho" a la contestación y la reivindicación.

En el caso de Yesica, se trata de aquellos elementos bolivianos de una identidad en formación que todavía no podían emerger dentro de una institución que tiene como una de sus principales tareas la transmisión de un sentido de la identidad nacional y con el que contribuye a la construcción de lo que Benedict Anderson denominó "comunidad imaginada" (1991). Lo inconfesable, lo indecible, entonces, eran aquellas prácticas que se llevaban a cabo en un mundo íntimo, pero que en la escuela entraban en tensión con otras prácticas y valores, y con la historia y la memoria oficiales.

Identificar los espacios de sociabilidad relacionados con la vida privada de la comunidad boliviana de Quilmes resulta una tarea compleja. En principio, el lugar que representaría la intimidad es el hogar. Los recuerdos que nuestra entrevistada reconstruye se basan en imágenes de una vida cotidiana en la cual las comidas típicas que su madre cocinaba a diario tienen un lugar fundamental, sumado a las melodías de un acordeón que su papá ejecutaba en el tiempo libre. Por ejemplo, cuando evoca su infancia, la sopa de maní que se compartía en familia aparece recurrentemente porque se convirtió en uno de sus platos predilectos

Sin embargo, no todas las remembranzas de aquella vida íntima son felices. Yésica recuerda que en ocasiones debía ausentarse a los cumpleaños de sus amigas de la escuela por asistir, por ejemplo, a un velatorio de algún miembro de la comunidad que ni siquiera conocía. Esto provocaba en ella un enfado al que su madre respondía evocando un pasado que, aunque Yésica no había vivido, la constituía como miembro de la comunidad. La madre aprovechaba esas ocasiones para reforzar el sentido de pertenencia de su hija al grupo: “Tenemos que estar porque somos paisanos, porque somos de la misma colectividad". 
En este sentido, es preciso recordar que cuando los padres de Yésica llegaron a la Argentina las redes de parentesco fueron cruciales para franquearles el acceso al mercado de trabajo, la vivienda y la información necesaria para descifrar los códigos propios de una nueva sociedad que ellos desconocían, además de constituir una malla de contención afectiva, que era vital a la hora de afrontar los costos emocionales de la migración. De este modo, se van revelando las tensiones propias de un proceso identitario complejo entre las dos generaciones.

Lejos de constituir un caso excepcional, se trata de un fenómeno común, aunque con sus propios matices, en las experiencias migratorias que involucran a padres extranjeros y a niños que nacen en el país de acogida, o bien llegan a él siendo pequeños. Por ejemplo, el caso de los niños lituanos en Buenos Aires que se incorporaron a una densa red de prácticas y asociaciones étnicas (Bjerg, 2012), o los de otras comunidades europeas radicadas en nuestro país (Silveira, 2017) que también vivieron en un mundo moldeado por adultos, dentro de relaciones de reciprocidad de las cuales no pudieron sustraerse.

En esos espacios y a través de distintas estrategias, sus padres les inculcaron la disciplina laboral como un valor. Por ejemplo, la obligación de levantarse de madrugada y, después del mercado, asistir a la escuela. De ese modo, intentaron demostrarles cómo se puede lograr la movilidad económica trabajando intensamente para conseguirlo. Aunque podríamos decir que esa característica también es propia de otras comunidades de inmigrantes, la particularidad del caso boliviano es que, al involucrar a sus hijos desde muy temprana edad, desafían el estándar moral que sanciona el trabajo infantil en la Argentina.

Los adultos integrarán a la segunda generación a través de la transmisión de estándares como el que venimos de mencionar. En este punto podríamos preguntarnos: ¿cómo incluir en un mismo relato, en una memoria colectiva y en un sentido de lealtad a una comunidad étnica a unos niños que no tuvieron la experiencia migratoria? Sostenemos que una de las maneras que articuló la primera generación fue trazar y fijar en la memoria de su descendencia el conocimiento de los derroteros esforzados y las magras condiciones de vida que sus padres recorrieron.

Con el tiempo, la experiencia de la migración va a transformarse en un patrimonio de todo el grupo que, a nuestro juicio, se expresa como un legado cultural. Ese legado descansa en la transmisión oral.

En nuestro caso, los jóvenes como Yésica sintieron que la combinación de una socialización argentina y boliviana era un camino intrincado "entre dos mundos", como lo afirma nuestra entrevistada. El Mercado Frutihortícola y las ferias itinerantes serán los ambientes laborales de la mayoría de los inmigrantes. Sin embargo, lejos de ser un espacio donde convergen únicamente adultos para llevar a cabo transacciones comerciales, es un lugar que alberga a niños y niñas que trabajan desde muy temprana edad junto a sus padres.

De ese modo, para Nélida, la inmigrante a la que aludimos más arriba, la crianza y el cuidado de sus hijos estuvo repartido entre la casa y el trabajo. Por lo general, el cuidado materno se representa como una actividad asociada al hogar. Sin embargo, Nélida relata que ha criado a sus hijos "debajo de la mesa" del mercado; es decir, debajo de su mostrador de venta. Este dato, aparentemente pequeño, es relevante porque echa luz sobre la diversidad de espacios de socialización de los hijos de la primera generación de inmigrantes bolivianos.

José Luis, ${ }^{6}$ otro de nuestros entrevistados, hoy tiene veintisiete años, nació en Bolivia y llegó a la Argentina a los cinco años. Nos contó que sus padres migraron buscando un empleo. Su papá era albañil y antes de traer a su familia vino solo para conseguir un lugar donde ellos pudieran vivir. Un año más tarde, cuando José Luis y su madre llegaron, ella comenzó a vender frutas en el mercado y luego ropa interior en una feria a la que él la acompañaba. Cuando José Luis rememora las mañanas en la feria, no se representa como un niño que sólo está esperando que pase el tiempo para que culmine la jornada laboral de su madre, sino que en su relato aparece como un pequeño trabajador:

Yo iba a vender con ella cuando era chico. Yo no hice Jardín. Entré directamente a..., creo que era la última salita. Entré a mitad de año y después entré a primero. Pero antes de eso yo iba con mi mamá, trabajaba con ella. Bah, vendía ropa interior, así. 
Yésica también recuerda las mañanas en el mercado participando activamente en ese espacio, como lo revela elocuentemente cuando dice:

Es así, vos ves que son las tres de la mañana y los chicos están ahí caminando con los papás en el mercado. Desde chiquitos, desde bebés, las madres los ponen en sus aguayos, en las mochilas y los llevan.

En estos casos, vemos cómo el pasado migratorio de la familia recobraba vitalidad a cada momento, cuando los adultos implementaban prácticas de cuidado de la infancia propias de su lugar de origen y, al mismo tiempo, transmitían a la segunda generación una experiencia de trabajo conjunto de padres e hijos que es aceptada y muy difundida en Bolivia.

En la memoria de la infancia de la madre de Yésica está grabada la experiencia de trabajar en el campo en familia, cosechar o sembrar desde las cinco de la mañana hasta casi el mediodía, para luego almorzar y asistir a la escuela. Esa misma rutina viviría muchos años después nuestra joven entrevistada junto a su madre en el Mercado Frutihortícola de Berazategui: se despertaba antes de las cinco de la mañana para comenzar la jornada laboral, que duraba hasta el mediodía cuando retornaban a su casa para almorzar y luego asistir a la escuela pública en Quilmes.

Los mercados y ferias, entonces, eran mundos pequeños pero muy significativos para estos niños que involuntariamente se vieron envueltos en las consecuencias de una experiencia migratoria y en los proyectos de movilidad de sus padres. Compartiendo los lugares de trabajo, aprendieron pautas del cuidado de la infancia que difieren de las prácticas argentinas, principalmente porque estar en ese ámbito implica no sólo esperar pasivamente que la jornada laboral culmine, sino que se les atribuirán tareas acordes a su edad. En el caso de Yésica y de José Luis, esa relación con el trabajo de sus padres y el aprendizaje del oficio los llevó a insertarse posteriormente en el mismo rubro. Desde hace algunos años, Yésica tiene un puesto propio, al lado del que sus padres instalaron hace más de treinta años. Por su parte, José Luis dividió su infancia entre acompañar a su mamá a la feria y a su papá al taller de aberturas de aluminio, donde trabaja en la actualidad.

Entonces, la socialización en la esfera íntima se llevó a cabo en el hogar y en los espacios donde sus padres desarrollaban la actividad laboral. En esos sitios, las relaciones interpersonales se circunscribían, en principio, al núcleo familiar conformado por padres y hermanos, pero se extendían hacia tramas más densas de parentesco, que incluyen a tíos y primos que están unidos a la primera generación mediante vínculos que, aunque pueden ser fuertes o débiles (Granovetter, 1974; Grieco, 1987), constituyen redes de reciprocidad que se gestaron en un pasado compartido. La segunda generación no pudo sustraerse a los compromisos entre parientes y paisanos que se gestaron mucho antes de que ellos nacieran. Esa circunstancia los hizo partícipes (voluntarios o no) de los acontecimientos sociales de la comunidad: bodas, cumpleaños, funerales.

De esa forma, se vincularon desde el comienzo de su vida con las prácticas étnicas de sus padres y construyeron desde pequeños una identificación con la comunidad. Los miembros de la segunda generación forman parte de un proyecto de movilidad social que sus padres trazaron y que, en el caso que estudiamos, lograron concretar. Para nuestros entrevistados, las experiencias rememoradas aparecen como sus primeros pasos en el mundo del trabajo: en sus relatos es recurrente la representación de la infancia como una instancia en la que sus progenitores no sólo los cuidaban sino que también les enseñaban a trabajar.

No obstante, como hemos señalado, aquellos niños también se socializaron en instituciones y espacios que compartían con niños y adolescentes argentinos; el central fue la escuela. Sin embargo, podemos inferir que resultaron relativamente impermeables a la experiencia escolar y a los objetivos de homologación cultural que la institución se propone. Sus compañeros de la escuela pública no eran interlocutores con los cuales compartir experiencias de la vida íntima, como la dieta o el trabajo de madrugada en los mercados mientras aquellos todavía dormían. Desde la adultez, Yésica evoca ese pasado manifestando que no sufrió, pero que esas diferencias en ocasiones eran "chocantes" y solían generarle incomodidad. Por ejemplo, luego de almorzar o cenar en familia, dentro de la comunidad, existe la costumbre de decir "Gracias”. Según Yésica, 
los inmigrantes más “ortodoxos" le dicen gracias personalmente a cada una de las personas que están en la mesa; otros dicen un "Gracias" general:

Yo no puedo terminar de comer y no decir "Gracias". Es más, o sea, mi tío... Bah, en su casa, mis primos dicen "Gracias" a cada uno, a todos los que comparten la mesa ¿Entendés? "Gracias” y te levantás de la mesa. Con mis amigas de Capital eso fue todo un tema.

Un hábito de la vida cotidiana y del dominio de lo familiar y lo cultural se convirtió para Yésica en una situación incómoda cuando comenzó a compartir las primeras comidas con sus amigas de la escuela y de la facultad, cuyas familias no observaban ese ritual.

El relato de José Luis, por otra parte, en apariencia no muestra tensiones entre el mundo público y el privado. Si bien, al igual que otros niños, trabajaba junto a su madre en la feria desde pequeño, las marcas de su identidad boliviana se desdibujaban en una socialización argentina, en el afuera. Él nos ha hablado de una infancia y adolescencia de amistades argentinas con las que jugaba al fútbol y concurría a las discotecas. Sin embargo, afirma: "Me crie con ellos hasta los 21 años". Entonces, las marcas identitarias bolivianas emergieron y se potenciaron. Como para tantos otros integrantes de la segunda generación, para José Luis y para Yésica, Los Caporales se transformaron en un espacio ritual de recuperación de la bolivianidad.

Tanto a ellos como a la mayoría de los entrevistados, les cuesta precisar la forma y el momento en que tomaron la decisión de participar en la fraternidad. Hablan de algo que surge casi espontáneamente, porque "la sangre tira" y hay que seguir al impulso. Como es bien sabido, en un relato de memoria el narrador no es un agente autónomo que ofrece un testimonio transparente sobre sus motivaciones, sino que en el acto de narrar gravita un complejo proceso social e histórico. El ingreso a Los Caporales se explica, entonces, en el contexto de las experiencias de socialización entre dos mundos de la segunda generación. Pero, a su vez, la recuperación de la identidad boliviana a través de esta danza ritual fue posible gracias a un proceso de movilidad social ascendente que registró la comunidad y que les permitió a los hijos de aquellos inmigrantes disponer de recursos materiales para llevar adelante una actividad artística y folklórica que fue volviéndose más sofisticada y costosa con el paso de los años.

Cabe señalar que para la primera generación la danza de Los Caporales (ni otras manifestaciones culturales similares) no jugó un rol significativo en el proceso identitario y de integración a la sociedad argentina. Ellos no crearon una trama en la que la identificación de la segunda generación pudiera sostenerse. No se trataba, por cierto, de una práctica desconocida puesto que formaba parte del despliegue de los carnavales en Bolivia, aunque es probable que la mayoría de ellos ni siquiera hubiese tenido contacto directo con ese espectáculo. Así las cosas, para la primera generación era casi imposible imaginar que sus hijos participarían de Los Caporales y que éstos adquirirían las dimensiones que tienen en la actualidad. En 2016 la fraternidad de Quilmes contaba con 120 miembros estables, en comparación con los cinco o seis que la conformaban en 1996.

Para la segunda generación realizar estas manifestaciones públicas significa mucho más que una demostración artística en la cual despliegan lo ensayado y planificado durante todo el año. En una fiesta como la que efectúan en Luján, los jóvenes toman conciencia de que son integrantes de una comunidad y, como sostiene el antropólogo Adrià Pujol Cruells, esa ocasión les otorga "la oportunidad de ponerse en escena, de ser al mismo tiempo protagonista y espectadora de su propia epifanía” (Cruells, 2006, p. 38).

\section{Reflexiones finales}

En este artículo, nos propusimos reconstruir una historia que involucra a dos generaciones y nos permite comprender por qué estos jóvenes realizan una actividad que, lejos de ser un simple acto de recreación, es una manifestación cultural que contiene tramas simbólicas densas en las que se sintetizan estrategias de integración configuradas a partir de sus propias experiencias como hijos de bolivianos en la Argentina. Esa integración se orienta no sólo hacia la sociedad local sino también hacia una comunidad de inmigrantes 
cuya potencia simbólica permeó sus trayectorias infantiles. De esa dinámica emerge una identidad nueva que, aunque se enraíza en las tramas culturales de la primera generación, está conformada por prácticas, espacios, símbolos y rituales de los que la segunda generación se apropia para expresar su singular filiación a una concepción de lo boliviano.

Sin embargo, para comprender las intenciones de estos jóvenes, decidimos estudiar cómo la generación de inmigrantes conceptualizó la comunidad en términos étnicos, poniendo el foco en los espacios que ocuparon dentro del mundo del trabajo. Así, vimos cómo las ferias, los mercados y talleres se constituyeron en lugares de sentido en los que los inmigrantes llegaron a reconocerse como una comunidad en una dinámica que, generalmente, involucraba a toda la familia. Sostenemos que en estos espacios, dominados por otros grupos nacionales, tuvieron lugar las primeras manifestaciones de la disputa por el poder cultural, cuando los bolivianos desplegaron sus propias tramas simbólicas dentro del Mercado Frutihortícola de Berazategui y de las ferias itinerantes.

La reconstrucción de ese pasado fue posible gracias al entrecruzamiento de distintas fuentes. Trabajamos principalmente con narrativas personales en las que nuestros entrevistados, mediante el ejercicio de la memoria, evocaban de manera fragmentaria sus recuerdos más significativos. En esas narrativas confluyen distintas temporalidades que nos permitieron reconstruir los derroteros de dos generaciones y enmarcar las historias que nos contaron dentro de contextos históricos. Por esta razón, como fuente secundaria echamos mano de la rica bibliografía que, desde distintas disciplinas, se ocupó de analizar el derrotero de la inmigración boliviana, sus formas de inserción laboral y de asentamiento. Ese acervo de investigaciones funcionó como cuadro general del cual nos valimos para darles sentido a las trayectorias personales relatadas. Este trabajo historiográfico, además, se benefició con la utilización de observaciones participantes que nos permitieron contrastar desde el presente los cambios en los lugares de socialización más importantes para las dos generaciones.

En el caso de la segunda generación, atendimos especialmente a la construcción de la subjetividad de aquellos niños, ahora jóvenes. Las historias de quienes lideran la creación y proliferación de la danza de Los Caporales adquieren sentido tanto para nosotros como para ellos mismos, dentro de trayectorias en las que las referencias al pasado migratorio de los padres fueron constantes y significativas, especialmente porque los mercados y ferias constituían, tanto como el hogar, un dominio en el que los niños nacidos en la Argentina eran socializados como bolivianos. A nuestro juicio, la adopción de un enfoque generacional enriquece la perspectiva de análisis del complejo proceso de configuración y reconfiguración de identidades étnicas, dado que éstas se encuentran inexorablemente atravesadas no sólo por cambios generacionales sino también por tensiones entre las generaciones.

Cuando la segunda generación comenzó a disputar poder cultural, tanto hacia afuera como hacia adentro de la comunidad, tuvo lugar un proceso de etnización y de institucionalización diferente del que había experimentado la primera generación. Este proceso fue posible en el marco de una dinámica de movilidad social y económica de la comunidad.

Este análisis también contribuye a pensar a la comunidad boliviana en la Argentina como un grupo que es heterogéneo en varios sentidos. Las posiciones sociales y económicas diversas que presentan los miembros del grupo a través del tiempo y del espacio ponen en cuestión los análisis, principalmente provenientes de la antropología, que ubican a los bolivianos en el terreno de la subalternidad, a pesar de las diferencias que existen en una comunidad tan amplia. Sostenemos que partir del supuesto de la vulnerabilidad cultural de un grupo obtura la posibilidad de comprender los procesos de movilidad social y económica y los mecanismos que una comunidad articula para hacerse visible integrándose a partir de sus propias experiencias y representaciones.

\section{REFERENCIAS}

Anderson, B. (1991). Imagined Communities. Nueva York: Verso. 
Benencia, R. (1997). De peones a patrones quinteros. Movilidad social de familias bolivianas en la periferia bonaerense. Estudios Migratorios Latinoamericanos, 12(35). 63-102

Benencia, R. (2004). Trabajo y prejuicio. Violencia sobre inmigrantes bolivianos en la agricultura periférica de Buenos Aires. Revue européenne des migrations internationales, 20(1), 97-118.

Bertoni, L. A. (2001). Construir la nacionalidad: héroes, estatuas y fiestas patrias. 1887-1991. Buenos Aires: Boletín del Instituto de Historia Argentina y americana, Dr. Emilio Ravignani.

Bjerg, M. (2009). Historias de la inmigración en la Argentina. Buenos Aires: Edhasa.

Cassanello, C. (2016). Migración, identidad y memoria. Los bolivianos en la Argentina. Quilmes: Universidad Nacional de Quilmes.

Cruells, A. P. (2006). Ciudad, fiesta y poder en el mundo contemporáneo. LiminaR. Estudios Sociales y Humanisticos, 4(2), 36-49.

Devoto, F. (2003). Historia de la inmigración en la Argentina. Buenos Aires: Sudamericana.

Gjerde, J. (1999). Identidades múltiples y complementarias: inmigrantes, líderes étnicos y el Estado en los Estados Unidos. Estudios migratorios latinoamericanos, 14(42), 3-23.

Granovetter, M. (1974). Getting a job. Cambridge: Harvard University Press.

Grieco, M. (1987). Keeping it in the family. Social networks and employment chance. Londres: Routledge.

Grimson, A. (1999). Relatos de la diferencia y la igualdad: los bolivianos en Buenos Aires. Buenos Aires: Eudeba.

Hall, S. (2010). Sin garantias. Trayectorias y problemáticas en estudios culturales. Popayán: Envión Editores.

Conzen, K.; Morawska, E; \& Vecoli, R. (1991). The invention of ethnicity: a perspective from the U.S.A. Journal of American Ethnic History, 12(1), 4-41.

Krase, J. (2009). Contested Terrains: Visualizing Glocalization in Global Cities. Open House International, 34(3), 65-73.

Lida, M. (2010). ¡A Luján! Las comunidades de inmigrantes y el naciente catolicismo de masas, 1910-1934. Revista de Indias, 70(250), 809-836.

Pizarro, C. (2007). Inmigración y discriminación en el lugar de trabajo. El caso del Mercado Frutihortícola de la colectividad boliviana en Escobar. Estudios Migratorios Latinoamericanos, 211-243.

Pollak, M. (1989). Memoria, esquecimiento, silencio. Revista de Estudos Históricos, 2(3), 3-15.

Silveira, A. (2017). Gran Bretaña en la Reina del Plata. Ingleses y escoceses en Buenos Aires 1800-1880. Buenos Aires: Biblos.

\section{Notas}

1 Sobre las diversas nociones de generación, ver Fulbrook, 2011.

2 Registros de los años 2010 y 2016 de la Asociación de Conjuntos Folklóricos de Residentes Bolivianos en Argentina.

3 Observación participante realizada por la autora el 06/08/2016 en la Ciudad de Luján.

4 Entrevista realizada por la autora a Nélida Hinojosa el 21/08/2017.

5 Entrevista realizada por la autora a Yésica durante el año 2017.

6 Entrevista realizada por la autora a José Luis el 11/03/2018. 